\title{
Zonas de Reserva Campesina: territorialidades en disputa. El caso del Valle del río Cimitarra, Colombia ${ }^{1}$
}

Peasant Reserve Zone: territorialities on dispute. The case of the Valle del río Cimitarra, Colombia

\author{
Claudia Quijano-Mejía* \\ Johana Linares-García**
}

\section{Resumen}

Las Zonas de Reserva Campesina-ZRC surgen como una herramienta jurídica que permite la defensa del territorio campesino, mediante el fortalecimiento de su economía, la formalización de la propiedad, la prevención y/o corrección de la concentración de la tierra y el cierre de la frontera agrícola. Mediante un estudio de caso se analiza la Zona de Reserva Campesina del Valle del Río Cimitarra ZRC-VRC, donde procesos de organización comunitaria demuestran el esfuerzo de regulación por parte del campesinado sobre los recursos naturales, la distribución de la tierra y la convivencia. Pero al mismo tiempo, desde el Estado se impulsan proyectos extractivistas ligados a la agroindustria de la palma, el latifundio, la minería de oro y la explotación de hidrocarburos. Esta situación pone en riesgo el desarrollo de los objetivos de la ZRC referentes al fortalecimiento

${ }^{1}$ Este artículo es producto de los resultados preliminares del proyecto de investigación Reconstrucción de la memoria histórica de la Asociación Campesina del Valle del río Cimitarra-ACVC desde un enfoque de género, financiado por Colciencias en el marco de la convocatoria 745 de 2016 y ejecutado por el grupo Población Ambiente y DesarrolloGPAD de la Universidad Industrial de Santander, Colombia.

* Trabajadora social, Magister en Estudios Latinoamericanos. Docente investigadora de la escuela de Trabajo Social, Universidad Industrial de Santander, Colombia. Correo electrónico: cmquijam@uis.edu.co

${ }^{* *}$ Trabajadora social, Magister (C) en Ordenamiento territorial. Docente investigadora de la escuela de Trabajo Social, Universidad Industrial de Santander, Colombia. Correo electrónico: linaresjohana@gmail.com

Recibido: 25 de Abril de 2017 Aprobado: 2 de septiembre de 2017

ISSN: 0122-1213 (Impreso) ISSN: 2389-993X (En línea) Doi: 10.25100/prts.v\%vi\%i.4478 Prospectiva. Revista de Trabajo Social e intervención social No. 24, julio-diciembre 2017: pp. 225-251 
del territorio campesino y limita las posibilidades de esta iniciativa agraria en la construcción de paz.

Palabras clave: Zonas de Reserva Campesina; Territorio campesino; Territorialidad; Conflictividad; Movimientos socioterritorial; Valle del Río Cimitarra; Construcción de paz.

\section{Abstract}

The Peasant Reserve Zones - ZRC arose as a legal mechanism that allows for the defense of peasant territory through the strengthening of its economy, the formalization of property, the prevention and/or revision of land concentration and the closure of the agricultural frontier. However, its development has been marked by the conflict between the territorialities of the peasantry and the capital. In this article, the Peasant Reserve Zone of the Cimitarra river Valley - ZRC-VRC is analyzed through a case study methodology, where community organization processes demonstrate the effort of regulation over natural resources, land distribution and coexistence. Nonetheless, at the same time, extractive projects linked to the palm agribusiness, large scale land ownership, gold mining and the exploitation of hydrocarbons are being promoted by the State. This situation jeopardizes the development of the objectives of the ZRC with regards to the strengthening of peasant territory and limits the possibilities of this agrarian initiative in the construction of peace.

Keywords: Peasant Reserve Zones; Peasant territory; Territoriality; Territorial conflicto; Cimitarra river Valley; Peace building.

Sumario: 1. Introducción; 2. Aspectos metodológicos; 3. Algunas consideraciones legales sobre la figura de Zona de Reserva Campesina; 4. Territorio, territorialización y movimientos socioterritoriales; 5. Territorialización campesina en el valle delrío Cimitarra; 6. Territorialización del capital en el valle del río Cimitarra; 7. Consideraciones finales; 8. Referencias bibliográficas. 


\section{Introducción}

En Colombia, la tenencia de la tierra refleja las brechas de exclusión dadas por su inequitativa concentración. Esto llevó al campesinado a movilizarse para exigir sus derechos sobre la propiedad de la tierra como elemento fundamental para mejorar su calidad de vida. Es así como en 1994 con la Ley 160 (República de Colombia) y el posterior Decreto 1777 de 1996, se establece el marco normativo que a través de las Zonas de Reserva Campesina - ZRC reconoce a las comunidades rurales su participación directa en la planificación de su territorio, pensado a partir de las particularidades sociales, culturales, políticas, económicas y ambientales que lo componen. No obstante, el desarrollo de las ZRC como parte de la Reforma Agraria del país de la década de los 90 ha estado en constante confrontación con los intereses de capital que con su sesgo económico obstaculiza la gestión territorial participativa de las ZRC y las propuestas de territorialidad campesina.

En este documento se analiza el caso de la ZRC del Valle del Río Cimitarra - ZRC-VRC, donde se gestan cuatro experiencias de territorialización campesina que demuestran el esfuerzo de regulación por parte del campesinado sobre los recursos naturales, la distribución de la tierra y la convivencia. En contravía, y a la par de las apuestas de la ZRC, se implementan en este territorio proyectos extractivistas que entran en disputa con el territorio campesino.

Es así como a partir de una metodología de corte interpretativo se busca mediante el estudio de caso único reflejar las contradicciones presentes en este territorio donde los agentes comunitarios "demandan la construcción de una territorialidad propia a través de planes de desarrollo autónomos" (Silva, 2016, p. 633). De esta manera, se expone el caso partiendo de algunas consideraciones legales sobre las figuras de las Zonas de Reserva Campesina, una breve conceptualización alrededor de territorio, territorialización y movimientos socioterritoriales, para luego describir y analizar las contradicciones entre las propuestas de territorialización campesina y del capital. 
El análisis de las ZRC adquiere vital importancia en el contexto actual de implementación de los acuerdos de paz entre las FARC-EP y Gobierno Nacional, que en el punto uno "Hacia un Nuevo Campo Colombiano: Reforma Rural Integral", las reconoce como iniciativas campesinas para la construcción de paz, estableciendo que el Gobierno Nacional promoverá el acceso a la tierra y la planificación de su uso en las ZRC, en acuerdo con las comunidades y organizaciones campesinas representativas, de tal manera que las ZRC logren su objetivo de fortalecer la economía campesina, cerrar la frontera agrícola y garantizar la producción de alimentos (FARC-EP; Gobierno Nacional, 2016).

\section{Aspectos metodológicos}

El estudio tiene un diseño cualitativo de corte interpretativo a partir del Estudio de Caso Único. Para Yin, una de las características de este tipo de investigación es el estudio de un fenómeno contemporáneo en su contexto real (Yin, 1989). Por lo tanto, el objetivo se centró en la comprensión del caso de la ZRC-VRC como un caso típico que permite vislumbrar la conflictividad actual en otras ZRC del país. Sin embargo, para el presente estudio el análisis se centra en la ZRC-VRC porque como plantea Stake: "El objetivo primordial del estudio de un caso no es la comprensión de otros. La primera obligación es comprender este caso" (Stake, 1999, p. 17)

Las fases del método fueron cuatro: 1) preparatoria, 2) de gestión de información, 3) analítica y 4) informativa (Rodríguez, Gil, \& García, 1996). En la primera fase se revisaron investigaciones en torno a las ZRC, se seleccionó y definió el caso de la ZRC-VRC y se construyó la guía de preguntas para la recolección de información en la fase dos, cuyo propósito se centró en la gestión de información secundaria (investigaciones, documentos de la organización y cartografía) y contrastación con fuentes primarias (entrevistas y diálogos informales con actores clave). Para el análisis de la información se siguió la lógica del tratamiento de datos cualitativos que va desde su reducción, disposición, transformación, formulación hasta la verificación de conclusiones (Rodríguez, Lorenzo 
y Herrera, 2005). Finalmente, en la cuarta fase los esfuerzos de las investigadoras se centraron en la producción escrita de los hallazgos.

\section{Algunas consideraciones legales sobre la figura de la Zona de Reserva Campesina}

La Zona de Reserva Campesina es una figura legal contemplada en la Ley 160 de 1994, reglamentada mediante el Decreto 1777 de 1996 y cuyos procedimientos de selección y delimitación se establecen en el Acuerdo 024 de 1996 del INCORA. A pesar de los casi 20 años de existencia legal, el tema solo ganó espacio en los medios masivos de comunicación a partir de las negociaciones entre el Gobierno Nacional y la guerrilla de las FARC y las movilizaciones campesinas del segundo semestre de 2013, particularmente la adelantada por campesinos colonos de la región del Catatumbo, que exigían que allí fuese constituida una Zona de Reserva Campesina como forma de resolver los problemas del agro en la región (Revista Semana, 2013)

Actualmente, en el país existen seis ZRC legalmente constituidas: ZRC del municipio de Cabrera, (Cundinamarca); ZRC Perla Amazónica, en el municipio de Puerto Asís (Putumayo); ZRC de los municipios de Morales y Arenal (Bolívar); ZRC del Guaviare en los municipios de San José del Guaviare, El Retorno y Calamar (Guaviare); ZRC Cuenca del río Pato y valle del Balsillas, en el municipio San Vicente del Caguán (Caquetá); y la ZRC del valle del río Cimitarra en los municipios de Yondó y Remedios (Antioquia) y San Pablo y Cantagallo (Bolívar). Además, están en proceso de constitución las Zonas de Reserva Campesina de Los Montes de María, departamentos de Bolívar y Sucre; Catatumbo, en Norte de Santander; Ariari, Güejar y Cafre, en el Meta; Losada Perdido, también en el Meta; Chimichagua, Pailitas, Curumaní y Chiriguaná en el Cesar; y en Sumapaz, Localidad 20 de Bogotá D.C.

El presente análisis se desarrollará sobre la Zona de Reserva Campesina del Valle del río Cimitarra (ZRC-VRC), que comprende los municipios de Cantagallo, San Pablo (Bolívar), Remedios y Yondó (Antioquia) (Véase Mapa 1). La Resolución 028 de 2002 del Instituto Colombiano 
de Desarrollo Rural, INCODER, mediante la cual se crea la ZRC-VRC, establece la casi totalidad del municipio de Yondó como parte de esta figura legal, sin embargo, los municipios de San Pablo, Cantagallo y Remedios en los que se ha desarrollado el proceso de colonización campesina y en los que la organización comunitaria también reivindica la ZRC-VRC, aún permanecen bajo la figura de Zona de Reserva Forestal (ZRF) de la ley 2 de 1959, siendo incompatible la existencia de las dos figuras legales en un mismo territorio. Por ello, se habla de ZRC-VRC constituida, es decir, la establecida en la Resolución 028 de 2002 del INCODER y la ZRC-VRC de hecho, es decir, en la que el proceso organizativo de las comunidades reivindica la figura. Además, es importante aclarar que meses después de constituida la ZRC-VRC en el 2002, la figura fue suspendida por el Gobierno Nacional, y solo en el 2011 dicha suspensión fue levantada (Agencia Prensa Rural, 2011).

\section{Mapa 1. Localización geográfica de la Zona de Reserva Campesina del Valle del Río Cimitarra}

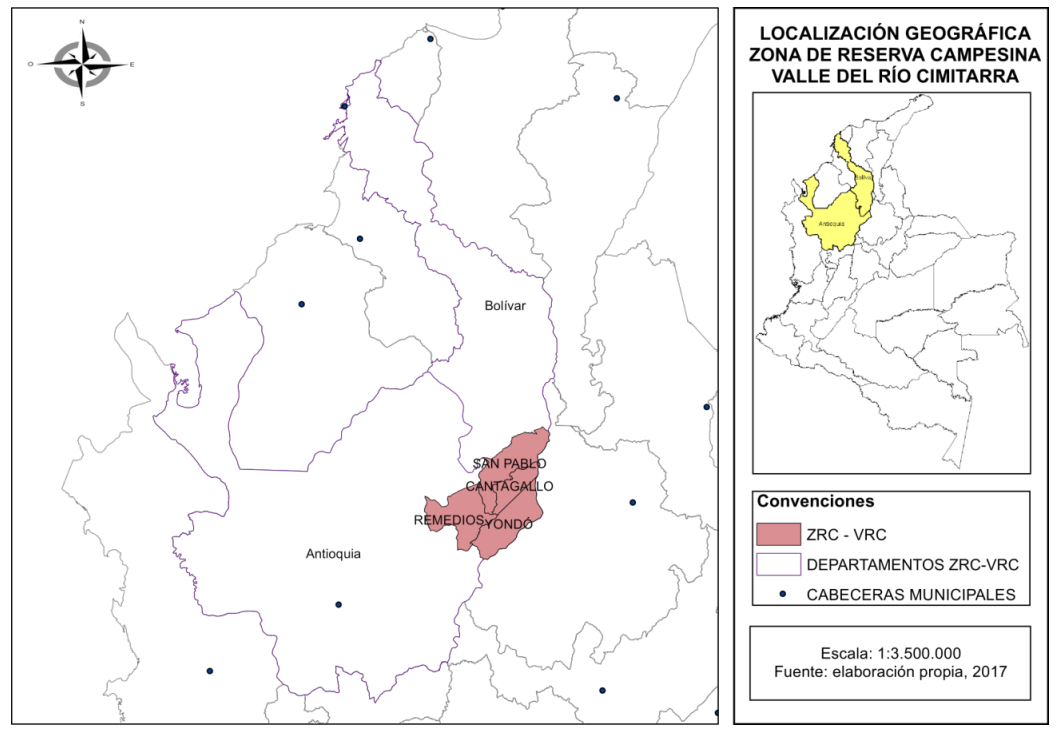

Fuente. Elaboración propia.

Uno de los primeros aspectos a ser discutidos sobre esta figura legal son los objetivos que desde la legislación vigente se le han asignado. Según Prospectiva. Revista De Trabajo Social e inTERVEnción SociaL No. 24, julio-diciembre 2019: pp. 225-251 
el Acuerdo 024 de 1996 del extinto Instituto Colombiano de Reforma Agraria, las ZRC tienen entre sus objetivos:

1. El control de la expansión inadecuada de la frontera agropecuaria.

2. La regulación, limitación y ordenamiento de la ocupación y aprovechamiento de la propiedad y la tenencia de predios y terrenos rurales.

3. La superación de las causas que vienen originando graves o excepcionales conflictos de orden social y económico, la preservación del orden público y el apoyo a los programas de sustitución de cultivos ilícitos

4. La adopción de estrategias o decisiones que tiendan a evitar o corregir los fenómenos de concentración de la propiedad, el acaparamiento de tierras rurales, o cualquier forma de inequitativa composición del dominio.

5. La protección y conservación de los recursos naturales renovables y del ambiente.

6. La creación de las condiciones para la adecuada consolidación y desarrollo de la economía campesina, buscando la transformación de los campesinos y colonos en medianos empresarios, dentro de principios de competitividad, sostenibilidad, participación comunitaria y equidad.

7. El fortalecimiento de los organismos de concertación de la reforma agraria y el desarrollo rural en los respectivos departamentos y municipios, así como de las organizaciones representativas de los colonos y campesinos, para garantizar su participación en las instancias de planificación y decisión regionales, así como la efectividad de sus derechos sociales, económicos y culturales.

8. El apoyo del Sistema Nacional de Reforma Agraria y Desarrollo Rural Campesino, del Sistema Nacional Ambiental y de otros organismos públicos y privados, para la formulación, financiación y ejecución de planes de desarrollo sostenible y de otras actividades, investigaciones, programas y proyectos que deban adelantarse en las zonas de reserva campesina (INCORA, 1996). 
Sin embargo, en la práctica, el desarrollo de las ZRC ha estado lleno de contradicciones y en muchos casos lo que ocurre en terreno va en contravía de los objetivos de esta figura. Es así como en la ZRC-VRC, se dan procesos de territorialización campesina, pero simultáneamente se desarrollan proyectos económicos que entran en conflicto con los propósitos de esta figura legal. Como señala Fernandes BM (Fernandes, 2005), las definiciones gubernamentales del y sobre el territorio, no consideran la conflictividad entre los diferentes tipos de territorio contenidos en un "territorio". Por un lado, el territorio campesino, que incluye fincas, producción agropecuaria a pequeña escala, productos de pancoger, caseríos y centros poblados; por otro lado, el territorio del capital, representado en el monocultivo de palma aceitera, la ganadería extensiva, la explotación minera y de hidrocarburos.

De um lado, o capital destrói e recria o campesinato, a partir de sua lógica e princípios. De outro lado, o campesinato também se recria, rompendo com a lógica e com os princípios do capital. A reprodução de ambas as formas de organização social são incongruentes, mas realizam-se no mesmo espaço, disputando territórios, gerando conflitualidade, promovendo desenvolvimentos (Fernandes, 2004, p. 8) ${ }^{2}$

\section{Territorio, territorialización y movimientos socioterritoriales}

El territorio ha sido definido desde diversas disciplinas que buscan a partir de él plantear ciertos problemas sociales, económicos, políticos y culturales. Aunque se ha convertido en un concepto integrador, en él se acentúan las relaciones de poder (Capel, 2016). Al respecto, Nates (2011) afirma que el territorio debe ser entendido como:

un escenario de poder, de gestión y de dominio del Estado, de individuos, de grupos y organizaciones y de empresas locales, nacionales y multinacionales, pero también como una superficie terrestre demarcada

\footnotetext{
${ }^{2}$ Por un lado, el capital destruye y recrea el campesinado, a partir de su lógica y principios. Por otro lado, el campesinado también se recrea, rompiendo con la lógica y con los principios del capital. La reproducción de ambas formas de organización social son incongruentes, pero se realizan en el mismo espacio, disputando territorios, generando conflictividad, promoviendo desarrollos
}

Prospectiva. Revista de Trabajo Social e intervención social No. 24, julio-diciembre 2017: pp. 225-251 
que conlleva una relación de posesión por parte de individuos y grupos y que contiene límites de soberanía, propiedad, vigilancia y jurisdicción ( $\mathrm{p}$. 211).

De esta manera, analizar la figura de ZRC a partir de la categoría territorio significa que sea considerada no solo como espacio de gobernanza, a partir de su delimitación geográfica determinada por la ley o las instancias gubernamentales (Flores, 2007) pues de ser así es solo una dimensión del análisis, sino, por el contrario, situar el debate en el territorio implica que el análisis de la ZRC aborde la conflictividad que le es propia (Pastrana, 2014).

Siguiendo los postulados de Fernandes (2004, 2005, 2008), se entiende que el territorio es un espacio político, es una construcción hecha a partir del espacio geográfico que le es anterior y cuyas transformaciones se dan por las relaciones sociales que lo impactan. El territorio comprendido apenas como espacio de gobernanza en sus diferentes escalas como municipio, departamento o nación, oculta las disputas territoriales que hay en su interior. Se hace necesario reconocer los otros tipos de territorios al interior del "territorio" formados por diferentes relaciones y clases sociales, para entender esta categoría en su complejidad. Así:

El territorio constituye un concepto teórico y un objeto empírico que $[\ldots]$ ha pasado del reduccionismo fisiográfico para ser asumido como un concepto que existe porque culturalmente hay una representación de él, porque socialmente hay una espacialización y un entramado de relaciones que lo sustentan y porque política y económicamente constituye una de las herramientas conceptuales más fuertes en la demarcación del poder y del intercambio (Llanos, 2010, p. 219).

En este sentido, el análisis de la ZRC-VRC debe superar su comprensión a partir de sus límites geográficos determinados por la Resolución 028 de 2002 o del análisis de los planes de desarrollo elaborados por las comunidades; se hace imprescindible evidenciar la conflictividad subyacente a la ZRC, entenderla como un territorio en disputa entre el campesinado y el capital. 
La conflictividad hace referencia al conjunto de conflictos que subyacen a la lucha por la construcción de diferentes tipos de territorio, es el proceso de enfrentamiento constante entre el territorio campesino y el territorio del capital, que corresponden a modelos de desarrollo divergentes y contradictorios, con organizaciones espaciales y paisajes geográficos completamente distintos. De la misma manera que suele pensarse la agroindustria y la explotación de hidrocarburos y minerales como generadores de desarrollo, asimismo, se entiende la ocupación de tierras y la lucha agraria como generadores de conflicto. Es necesario superar esta visión simplista y oficial sobre el territorio. Para ello, se debe comprender cómo los llamados proyectos de desarrollo - impulsados muchas veces desde la institucionalidad- también son generadores de conflictos y cómo las acciones del movimiento agrario también son generadoras de desarrollo (Fernandes, 2004).

A conflitualidade gerada pelo capital em seu processo de territorialização, destrói e recria o campesinato, excluindo-o, subordinando-o, concentrando terra, aumentando as desigualdades. A conflitualidade gerada pelo campesinato em seu processo de territorialização destrói e recria o capital, ressocializando-se em sua formação autônoma, diminuindo as desigualdades, desconcentrando terra. Essa conflitualidade promove modelos distintos de desenvolvimento (p. 8)

En esta línea de análisis interesa entender el concepto de soberanía: cuando el territorio es entendido como espacio de gobernanza la soberanía puede ser entendida como la autonomía de los gobiernos municipales, departamentales o nacionales en la toma de decisiones; y cuando nos referimos al territorio como propiedad individual o comunitaria la soberanía hace referencia a la autonomía de las poblaciones en la toma de decisiones concernientes al desarrollo de sus territorios (Fernandes, 2008).

\footnotetext{
${ }^{3}$ La conflictividad generada por el capital en su proceso de territorialización, destruye y recrea al campesinado, excluyéndolo, subordinándolo, concentrando tierra, aumentando las desigualdades. La conflictividad generada por el campesinado en su proceso de territorialización destruye y recrea el capital, resocializándose en su formación autónoma, disminuyendo las desigualdades, desconcentrando tierra. Esta conflictividad promueve modelos distintos de desarrollo
}

Prospectiva. Revista de Trabajo Social e intervención social No. 24, julio-diciembre 2017: pp. 225-251 
Para el caso de la ZRC-VRC las comunidades han logrado márgenes de autonomía frente al desarrollo de su territorio: han construido y organizado el territorio según su visión de mundo, han establecido normas de convivencia entre sus pobladores, han promovido la organización comunitaria y han emprendido proyectos productivos para la zona. Sin embargo, esta autonomía ha estado en constante disputa con otras formas de entender y construir el territorio bajo la lógica del capital, que entiende la tierra como una mercancía que debe estar sujeta a las leyes del mercado y como espacio de extracción de recursos naturales. Esta situación se evidencia, por ejemplo, en la definición por parte de entidades como la Agencia Nacional de Hidrocarburos y la Agencia Nacional de Minería, de amplias porciones territorios dentro de la ZRC-VRC para la exploración y explotación minero-energética (oro y petróleo) sin una previa interlocución y acuerdo con las comunidades. La ZRC-VRC es más que un espacio geográfico estático, es un espacio en disputa, en el que se crean y recrean la territorialidad campesina y la territorialidad del capital.

De esta manera se afirma lo expuesto por Silva (2016), para quien "el espacio es apropiado, dominado, gestionado y controlado, generándose así territorios múltiples. A este proceso de apropiación y de construcción sociopolítica por parte de actores se le denomina como territorialización, de carácter dinámico y conflictivo" (p. 43).

En este ámbito es determinante el papel de los actores sociales en la gestión del territorio, las ZRC son el reflejo de la lucha social por reinvindicar los derechos de los campesinos, en especial su derecho a la tierra, "los antecedentes de las ZRC se encuentran en 1985 en las movilizaciones y luchas campesinas dadas en las zonas de colonización del sur del país, específicamente en los territorios de la Macarena en el Meta y los ríos Duda y Caguán en Caquetá, regiones caracterizadas por el abandono estatal" (Cruz y González, 2014, p. 66).

Para el análisis de estos actores sociales, se pueden seguir los planteamientos de Zibechi (2007) respecto a los actuales movimientos sociales en Latinoamérica que, según el autor, tienen algunas características o tendencias comunes. Primero, la territorialización, es decir, el arraigo a los territorios que ocupan, conquistan o recuperan en sus luchas y desde 
los cuales construyen sus proyectos de vida y establecen alianzas con otros sectores populares. Segundo, la búsqueda de autonomía frente al Estado y a los partidos políticos, los movimientos sociales trabajan para garantizar su autonomía material y simbólica y asegurar la subsistencia de sus integrantes. Tercero, buscan la revalorización de su cultura e identidad reafirmando sus diferencias y particularidades étnicas, de género o de cualquier otra índole. Cuarto, la capacidad que tienen estos movimientos sociales para crear y formar sus propios intelectuales: la creciente escolarización trajo como consecuencia la formación de profesionales provenientes de las organizaciones populares, que mantienen su vinculación social y política con dichos procesos; asimismo, los movimientos sociales se han responsabilizado de la formación de sus propios dirigentes a partir de sus propias estrategias pedagógicas. Quinto, el nuevo papel de liderazgo ejercido por la mujer, evidenciando los cambios en la familia y las nuevas relaciones de género que se han establecido al interior de las organizaciones sociales. Sexto, estos nuevos movimientos sociales tienen una preocupación por la organización del trabajo y el cuidado de la naturaleza, les interesa crear relaciones igualitarias y sin jerarquías entre los dirigentes y sus bases, y al mismo tiempo, desarrollar actividades productivas que no sean depredadoras del medio ambiente. Y por último, las antiguas formas de acción como la huelga suelen ser sustituidas por acciones a través de las cuales se hacen visibles y reafirman su identidad, como por ejemplo, las "tomas".

Entre esas características o tendencias comunes de los movimientos sociales latinoamericanos, la territorialización, o mejor aún, la nueva territorialidad, es la característica más relevante y distintiva. Para ellos:

La tierra no se considera sólo como un medio de producción, superando una concepción estrechamente economicista. El territorio es el espacio en el que se construye colectivamente una nueva organización social, donde los nuevos sujetos instituyen su espacio, apropiándoselo material y simbólicamente (Zibechi, 2007, p. 26).

En esta línea de análisis, la ACVC junto con la ZRC-VRC como su bandera de lucha, es entendida como un movimiento socio territorial, por 
cuanto para esta organización campesina el territorio no es solamente su objetivo, sino que éste es imprescindible, vital, para su propia existencia. Además, actúa en una macroregión y en su lucha por la tierra y el territorio desenvuelve una serie de estrategias políticas para producir su propio territorio y promover su territorialización (Fernandes, 2005).

Los planteamientos de Agnew y Oslender (2010), también pueden ser útiles en la comprensión de las ZRC y, en específico, el caso del valle del río Cimitarra. Los autores plantean la noción de "territorialidades superpuestas" para entender la confluencia entre la autoridad territorial de los Estados-nación y otras fuentes no estatales de autoridad territorial. De ese modo, la territorialidad entendida como "el uso y control del territorio con fines políticos, sociales y económicos" no es exclusivamente estatal; ésta es solo una entre las múltiples formas de territorialidad posible. Las "territorialidades superpuestas", si bien se encuentran al interior de un estado determinado, no son necesariamente excluyentes, puesto que en muchos casos fue el mismo Estado que "reconoció, legitimó y promovió territorialidades no estatales dentro de sus fronteras", lo que eventualmente puede resultar en un fortalecimiento de la propia soberanía y legitimidad estatal y no necesariamente en un menoscabo de la misma (Agnew y Oslender, 2010, pp. 195-203).

El análisis de las ZRC desde la perspectiva socioterritorial permite entender las organizaciones campesinas como movimientos sociales que tienen el territorio como eje central de sus acciones y que apuestan por la construcción de un nuevo orden social. En otras palabras, "os diferentes movimentos sociais ressignificam o espaço e, assim, com novos signos grafam a terra, geografam, reinventando a sociedade. [...] Afinal, movimento é, literalmente, mudança de lugar e, assim, todo movimento social é, de alguma forma, em maior ou menor grau, portador de uma outra configuração social possível" (Porto-Goncalves, 2003, p. 6).

A continuación se presenta un cuadro global del estado actual de la conflictividad entre el territorio campesino y el territorio del capital en los cuatro municipios (Yondó, Remedios, Cantagallo y San Pablo) que componen la figura legal de la ZRC-VRC. Interesa exponer cómo la ZRC no es un espacio homogéneo en el que la organización campesina - o el 
mismo capital- ha logrado establecerse sin mayores dificultades, y sí una zona en la que diferentes tipos de desarrollo y territorio se encuentran en conflicto constante.

\section{Territorialización campesina en el Valle del río Cimitarra}

Lo que hoy se conoce como ZRC-VRC es el resultado de un proceso de colonización de tierras llevado a cabo hace más de 30 años por campesinos que salieron de sus lugares de origen desplazados por la violencia armada o la falta acceso a tierras. Alrededor de la colonización se gestó un proceso de organización comunitaria que reguló el acceso a los recursos naturales, la distribución de la tierra y creó normas de convivencia, como manifestaciones de territorialidad en las que el campesinado reclama "el reconocimiento social externo a la pertenencia al espacio a través de estos espacios de representación de habitar y construir un territorio" (Ruíz, 2015, p. 48).

En particular, en el valle del río Cimitarra se destacan cuatro experiencias significativas de territorialidad campesina: la Línea amarilla, el comité de tierras, La Cooperativa de pequeños y medianos productores de Antioquia, COOPEMANTIOQUIA y las Juntas de Acción Comunal veredales, estas últimas organizadas hoy a nivel municipal en la figura de las Mesas Comunales por la Vida Digna de la Región.

La línea amarilla es una demarcación hecha por los propios campesinos alrededor de los reductos de la serranía de San Lucas y que restringe el avance de la colonización. Los campesinos han llegado al acuerdo de que en esta zona está prohibida la caza, la explotación de maderas, la pesca o cualquier tipo de intervención sobre la fauna y la flora (Véase Mapa 2). Actualmente, la organización campesina adelanta acciones de protección de esta zona, entre ellas, en el Plan de Desarrollo Sostenible (ACVC, 2013) se contempla el proyecto Protección y ampliación del área protegida de la ZRC-VRC (Línea Amarilla) y entre abril y mayo de 2015 se realizó la caracterización biológica del sur de la serranía de San Lucas en alianza con universidades del país y la región, organizaciones y fundaciones ambientalistas y las Juntas de Acción Comunal de la zona, identificando 
áreas de protección y conservación biológica dentro de la ZRC-VRC (ACVC, 2015).

Mapa 2. Aptitud de uso de tierras y línea amarilla

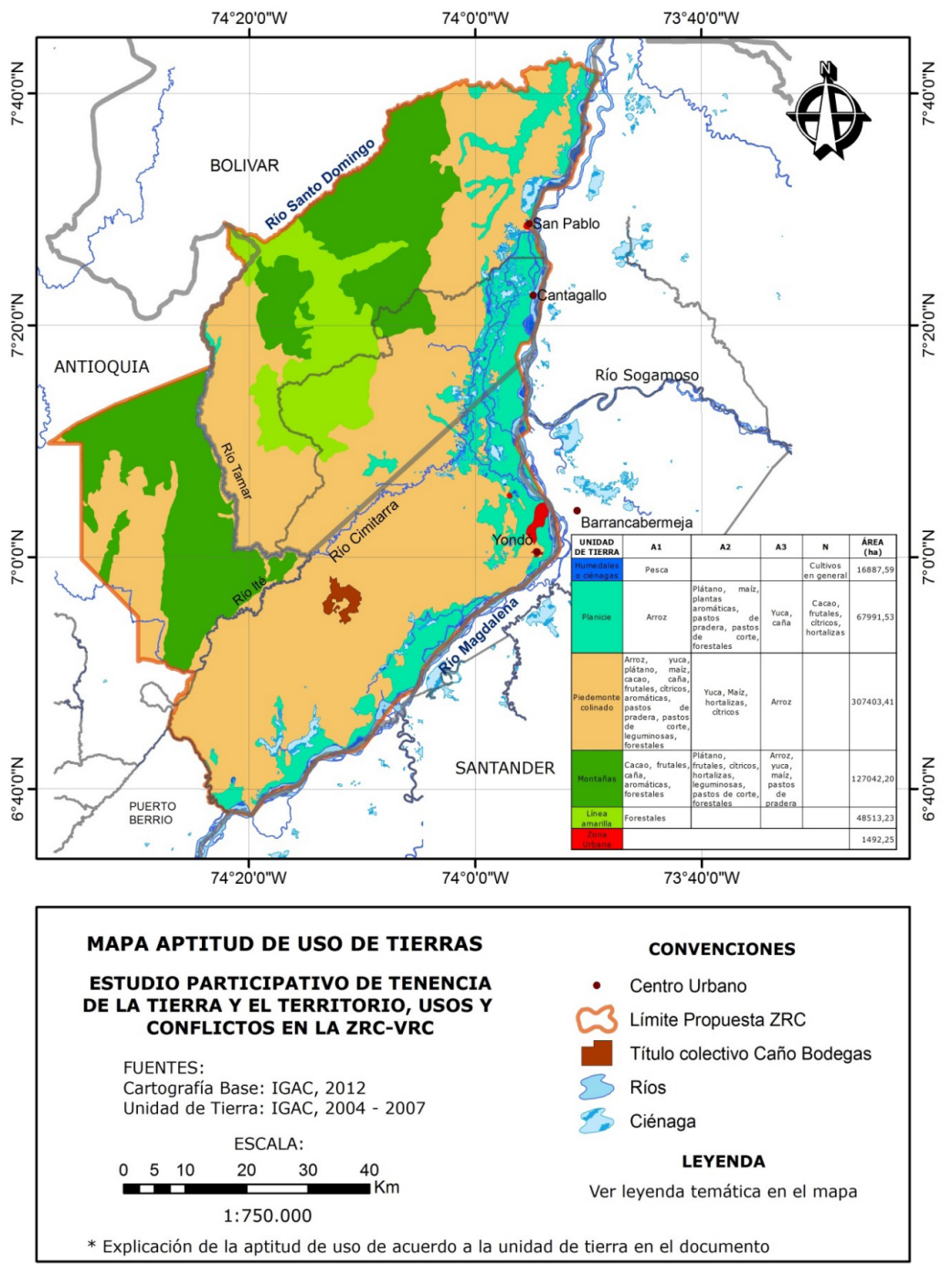

Fuente: Estudio Participativo de Tenencia de la Tierra y el Territorio, Usos y Conflictos en la ZRC Del Valle Del Río Cimitarra. PNUD-ACVC-SOLUTERRA 2014

Prospectiva. Revista de Trabajo Social e intervención social No. 24, julio-diciembre 2017: pp. 225-251 
En aras de fortalecer esta iniciativa, la organización campesina ha impulsado el desarrollo en la región del programa del Ministerio de Agricultura, Bosques de Paz, cuyo propósito es la integración de la conservación, la educación ambiental y lo productivo en zonas afectadas por el conflicto. De esta manera el 14 de septiembre de 2017 se hizo oficial el lanzamiento de este programa en la vereda de Puerto Matilde, del municipio de Yondó (Antioquia), como reconocimiento a la labor de conservación de cerca de 60.000 hectáreas de bosques por parte de las comunidades campesinas que habitan la región, mediante la iniciativa conocida como Línea Amarilla.

El comité de tierras existió entre 1988 y 1993, teniendo como función principal la demarcación de los nuevos predios, así como la identificación de aquellos que sobrepasaban las 200 hectáreas para luego ceder los terrenos a favor de los campesinos que no poseían tierras; dicho comité estaba integrado por los colonos que tenían más tiempo en la región y que gozaban de respeto en la comunidad. El comité de tierras es considerado un intento de reforma agraria emprendida desde el campesinado y, según Méndez (2013, pp. 85-87), se realizó mediante los siguientes criterios y procedimientos: el tamaño de los predios estuvo entre las 100 y 200 hectáreas dependiendo de la calidad del suelo, hubo auto-regulación en la explotación de los recursos naturales mediante el establecimiento de pautas comunitarias de protección de la fauna y la flora, el procedimiento y las responsabilidades dentro del proceso de adjudicación de terrenos estaba a cargo de la Junta de Acción Comunal, se establecieron una serie de normas comunitarias para la convivencia $\mathrm{y}$, por último, la nueva familia que entraba a hacer parte del proceso recibía apoyo mediante insumos, semillas, animales de corral y mano de obra comunitaria para la construcción de la vivienda.

La Cooperativa de pequeños y medianos productores de Antioquia -COOPEMANTIOQUIA, fue una iniciativa de economía solidaria que tenía como propósito comprar a un precio justo y sostenido el oro y la madera extraídos de la región por parte de los colonos, al tiempo que vendía víveres y enseres de primera necesidad a precios bajos mediante la implementación de tiendas comunitarias (Méndez, 2013, pp. 69-73). 
El intercambio de los productos campesinos evitaba abusos por parte de especuladores, garantizaba la comercialización de los productos agrícolas, al tiempo que era un mecanismo de resistencia campesina frente a los bloqueos alimentarios y sanitarios que se desarrollaban en la zona por ocasión del conflicto armado. COOPEMANTIOQUIA tuvo que enfrentar los constantes señalamientos y hostigamientos por parte de los grupos paramilitares y el Ejército Nacional, que interpretaban la iniciativa comunitaria como de apoyo a la subversión. En 1989 la sede principal de COOPEMANTIOQUIA, ubicada en la vereda Puerto Nuevo Ité fue bombardeada y saqueada por parte de Ejército Nacional, siendo presentada ante los medios de comunicación como un campamento guerrillero. Posteriormente, en 1996, varios paramilitares ingresaron a las veredas La Congoja, La Troja y Puerto Nuevo Ité, asesinaron a siete campesinos, quemaron el caserío de Puerto Nuevo Ité y la sede de la cooperativa (Equipo Nizkor y Derechos Human Rights eds., 2001, pp. 322-337).

Por último, debe destacarse la experiencia de las Juntas de Acción Comunal, espacio en el que la comunidad discute aspectos relativos a la convivencia en los caseríos tales como: horarios de funcionamiento de cantinas, uso de los espacios comunes, pastoreo de animales, riñas, establecimiento de periodos de veda para la pesca, interlocución con actores armados legales e ilegales para exigir el respeto a los Derechos Humanos y Derecho Internacional Humanitario, entre otros. Como resultado de este proceso de organización social, desde 2007 vienen funcionando las Mesas Comunales por la Vida Digna en la Región, espacio de discusión y debate de los principales problemas del municipio al que acuden las Juntas de Acción Comunal, asociaciones comunales y diversos tipos de organización comunitaria a debatir sobre el futuro del municipio y a generar propuestas para interlocutar con la administración municipal, es de destacar que uno de sus logros ha sido el establecimiento de Pactos de Gobernabilidad con los candidatos y gobernantes locales en elecciones de $2011^{4}$.

Además de la ZRC-VRC, en el año 2000 el Consejo Comunitario de negritudes ubicadas en la vereda Caño Bodegas del municipio de Yondó,

\footnotetext{
${ }^{4}$ Para la descripción de aspectos cotidianos de la organización campesina, se utilizan observaciones directas en campo entre los periodos 2013-2017.

Prospectiva. Revista de Trabajo Social e intervención social No. 24, julio-diciembre 2017: pp. 225-251
} 
solicita ante el INCODER la titulación colectiva de un terreno baldío en el mismo municipio. Así, el INCODER mediante resolución 1174 de julio de 2002, otorga el título de 2181 hectáreas a las comunidades negras de Caño Bodegas. En aquel entonces, y según la resolución de titulación colectiva, la comunidad de negritudes contaba con 48 familias, para un total de 210 personas. De acuerdo con la caracterización del Consejo Comunitario de Negritudes de Caño Bodegas realizada por el Programa de Desarrollo y Paz del Magdalena Medio (2012), actualmente el Consejo está integrado por 64 familias que se reconocen como afrodescendientes, afrocolombianas o de descendencia negra. Una particularidad de Caño Bodegas, es que los linderos de las fincas anteriores al título colectivo fueron respetados y, con ello, la autonomía de la familia en el aprovechamiento de la tierra.

Debe resaltarse que la comunidad de Caño Bodegas, contrario a la mayoría de campesinos del municipio, ha logrado la formalización de la propiedad mediante la titulación colectiva. En el municipio de Yondó los niveles de informalidad frente a la tenencia de la tierra son bastante altos, los campesinos realizan la compra y venta de sus tierras mediante contratos verbales y/o carta-ventas y en su mayoría no poseen títulos de propiedad, caso contrario al de la comunidad de Caño Bodegas, que sí posee título de propiedad, pero éste es de carácter colectivo. Al existir la formalización de la propiedad es posible acceder a créditos, subsidios y proyectos destinados al sector rural, que muchas veces tienen el título de propiedad como un requisito para participar. Es de suma importancia señalar que la existencia del título colectivo de comunidades negras en el municipio de Yondó, al igual que la ZRC-VRC, es una muestra de las luchas campesinas $\mathrm{y}$ afrodescendientes por la defensa del territorio.

\section{Territorialización del capital en el Valle del río Cimitarra}

Al tiempo que se desarrollan los procesos de territorialización campesina se implementan en la zona proyectos de tipo económico que van en contravía de los objetivos de la ZRC y que entran en disputa con el territorio campesino. Proyectos que, en general, son impulsados desde el propio Estado. En primera instancia, debe mencionarse la exploración 
y explotación de recursos naturales no renovables, específicamente los hidrocarburos y la minería de oro en los municipios que hacen parte de la ZRC-VRC. De acuerdo con el estudio participativo de tenencia de la tierra y uso del territorio (PNUD y ACVC, 2014) para la ANH alrededor del $80 \%$ del territorio del municipio de Yondó presenta algún tipo de actividad relacionada con el sector de hidrocarburos, asimismo, importantes áreas de los territorios de Cantagallo, San Pablo y Remedios presentan áreas con exploración y explotación de hidrocarburos (Véase Mapa 3).

\section{Mapa 3. Mapa de conflictos de sobre posición de títulos}

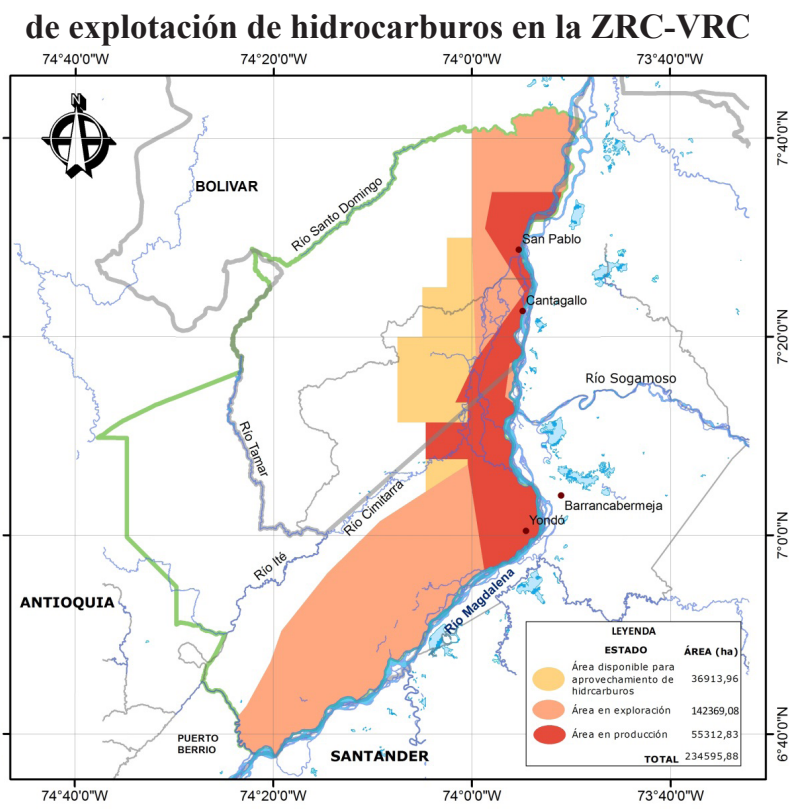

\begin{tabular}{|c|c|}
\hline \multicolumn{2}{|c|}{$\begin{array}{l}\text { MAPA DE CONFLICTOS DE SUPERPOSICIÓN DE TÍTULOS } \\
\text { ENERGÉTICOS CON ÁREAS DE COLONIZACIÓN CAMPESINA }\end{array}$} \\
\hline $\begin{array}{l}\text { ESTUDIO PARTICIPATIVO DE TENENCIA } \\
\text { DE LA TIERRA Y EL TERRITORIO, USOS Y } \\
\text { CONFLICTOS EN LA ZRC-VRC }\end{array}$ & $\begin{array}{l}\text { CONVENCIONES } \\
\text { - Centro Urbano } \\
\text { Límite de Municipio }\end{array}$ \\
\hline $\begin{array}{l}\text { FUENTES: } \\
\text { Cartografía Base: IGAC, } 2012 \\
\text { Títulos de hidrocarburos: ANH, } 2013\end{array}$ & $\begin{array}{l}\text { Limites de Departamento } \\
3 \text { Limite propuesta ZRC }\end{array}$ \\
\hline ESCALA: & $\sum$ Ríos \\
\hline $\begin{array}{llll}0 & 5 & 10 & 20 \\
\end{array}$ & \& Ciénaga \\
\hline $1: 750.000$ & $\begin{array}{c}\text { LEYENDA } \\
\text { Ver leyenda temática en el mapa }\end{array}$ \\
\hline
\end{tabular}

Fuente: Estudio Participativo de Tenencia de la Tierra y el Territorio, Usos y Conflictos en la ZRC Del Valle Del Río Cimitarra. PNUD-ACVC-SOLUTERRA 2014 
Si bien la actividad petrolera ha sido un factor determinante en los procesos de colonización del Magdalena Medio (Murillo, 1994), hoy se presenta como un obstáculo para el desarrollo de la figura de la ZRC, específicamente lo concerniente a la formalización de la propiedad rural, pues hay una limitación normativa en la Ley 160 de 1994 y en el Decreto 2664 de 1994 del Ministerio de agricultura y desarrollo rural -mediante el cual se reglamenta el capítulo XII de la misma ley -que señalan como baldíos inadjudicables aquellos que se encuentren en un radio de $5 \mathrm{~km}$ alrededor de los sitios en los que se lleva a cabo la explotación de recursos naturales no renovables. Aunque la ley es clara al señalar que la prohibición recae sobre aquellos terrenos que se encuentran alrededor de zonas de explotación, en la práctica estas áreas resultan de difícil definición, pues la información disponible en la página de la Agencia Nacional de Hidrocarburos-ANH cuando señala los pozos lo hace sin aclarar si estos son productores o no, y cuando especifica las áreas en exploración y explotación lo hace mediante bloques y no mediante puntos, lo que en la práctica impide que en una vasta extensión del territorio de la ZRC haya posibilidades de formalización de la propiedad. A ello se suma que las actuales áreas que se encuentran en exploración, podrían pasar en algún momento a la fase de explotación dejando prácticamente la totalidad del municipio como terreno inadjudicable y, por lo tanto, imposibilitando la formalización de la propiedad rural.

Situación similar ocurre con el monocultivo de palma africana, que actualmente ocupa la mayor parte del área plana del municipio de San Pablo (Bolívar). Los cultivos de palma aceitera eran pequeños en la región, pero hacia el año 2006 se impulsa su siembra con el apoyo de la USAID, Acción Social y la OEA, llegando a 4.000 hectáreas en tan solo un año; actualmente se estima que en el municipio hay más de 11.000 hectáreas de palma de aceite en producción (FEDEPALMA, 2012). Si bien en la región se impulsó la siembra de palma por parte de campesinos y/o pequeños agricultores mediante el programa Finca Campesina del Programa Desarrollo y Paz del Magdalena Medio, la realidad es que alrededor del 70\% de los cultivos son de tipo empresarial o corresponden a grandes plantaciones (Blanco, 2012, p. 75). El monocultivo de palma se presenta contrario a la territorialidad 
campesina por cuanto desestimula la producción de alimentos al cambiar el uso del suelo, al tiempo que favorece la transformación de jóvenes campesinos en trabajadores rurales.

En cuanto a la explotación de oro, debe mencionarse que en el territorio de la ZRC-VRC, principalmente en el municipio de Remedios, se ha venido desarrollando la actividad minera a pequeña escala como principal actividad económica por parte de los colonos y campesinos que allí habitan, junto con la explotación maderera y los cultivos de pancoger. Al igual que los municipios de Cantagallo y San Pablo, la mayor parte del área rural del municipio de Remedios se encuentra bajo la figura de Zona de Reserva Forestal de Ley 2 de 1959, por ello no pueden solicitar ante la instancia competente, el INCODER ${ }^{5}$, la adjudicación del predio que ocupan, en algunos casos hace más de 40 años. Paralelamente, se calcula que en Remedios existen cerca de 62.480 hectáreas otorgadas en títulos mineros, muchos de ellos dados a grandes empresas, los cuales se encuentran en diferentes etapas: exploración, construcción o construcción y montaje (Catastro Minero Colombiano, 2013). Estas empresas para iniciar sus labores deben adelantar ante el Ministerio del Medio Ambiente la sustracción de la Zona de Reserva Forestal y así, una vez iniciadas las actividades de explotación habrá un nuevo impedimento para la formalización de la propiedad campesina, pues como ya se mencionó, la legislación actual prohíbe la adjudicación de baldíos en zonas de explotación de recursos no renovables.

Al panorama ya descrito se suma la existencia de latifundios ganaderos en la zona, principalmente en el extremo sur del municipio de Yondó. De acuerdo al Estudio participativo de tenencia de la tierra y el territorio, usos y conflictos en la ZRC del Valle del río Cimitarra (PNUD y ACVC, 2014), en el municipio de Yondó hay preponderancia de la mediana propiedad, por lo que 1.040 predios catalogados como pequeña propiedad son inferiores a 20 hectáreas y equivalente al 3,85\% del territorio rural del municipio, la mediana propiedad correspondiente a 1.519 predios con tamaños entre 20 y 200 hectáreas que equivalen al 56,3\% y, por último, la gran propiedad que ocupa el $39,7 \%$ del área rural municipal a través

${ }^{5}$ Hoy Agencia Nacional de Tierra- ANT

Prospectiva. Revista de Trabajo Social e intervención social No. 24, julio-diciembre 2017: pp. 225-251 
de 151 predios mayores a 200 hectáreas. Cabe señalar, que de esos 151 predios, 117 tienen una extensión que oscila entre las 200 y 500, ocupando un $19 \%$ del territorio rural del municipio y tan solo 34 predios mayores a 500 hectáreas corresponden al 20\% del área rural Yondosina.

Es de anotar que esas cifras pueden no corresponder necesariamente a la realidad y ser la situación de fragmentación improductiva o de concentración de la tierra aún peor, pues dichos datos son de las oficina de catastro municipal y, debido a la falta de formalización de la propiedad rural y la desactualización de los datos en esta área, se presenta subregistro de las transacciones propias del mercado de tierras, siendo que muchas son hechas mediante cartaventas o acuerdos verbales. Adicionalmente, según líderes de la ACVC (Guerra, 2015), durante la suspensión de la figura de la ZRC entre el 2003 y el 2011, élites económicas aprovecharon para expandir sus propiedades en la zona.

La existencia de propiedades con extensiones que superan las 500 hectáreas es un aspecto que merece especial atención, pues de acuerdo a la normatividad vigente la Unidad Agrícola Familiar (UAF) establecida para el municipio de Yondó oscila entre 53 y 72 hectáreas, y en la Resolución 028 de 2002, mediante la cual se constituye la ZRC-VRC, se estableció que es de 2,5 UAF, es decir, predios con un tamaño cercano a las 150 hectáreas. Además, es necesario considerar que Yondó antes de ser declarado municipio en 1978, pertenecía a la Zona de Reserva Forestal del Magdalena Medio de la Ley segunda de 1959 y debido a los procesos de colonización que se vivieron allí, fue necesario realizar un proceso de sustracción que permitiera el acceso formal a la tierra por parte de estos campesinos colonos. De esta manera, en 1976 mediante el acuerdo 002 del INDERENA y Resolución ejecutoria 050 del Ministerio de Agricultura, fueron sustraídas alrededor de 171.000 hectáreas de la Zona de Reserva Forestal del Magdalena ubicadas en los terrenos hoy pertenecientes al municipio de Yondó, con el objetivo de realizar procesos de adjudicación de tierras a los campesinos colonos que vivían allí (IDEAM, 2006, p. 107).

Sin embargo, lo que hoy se encuentra es que uno de los mayores problemas del municipio, enunciado de manera persistente por los campesinos y sus organizaciones, es la falta de formalización de la propiedad rural. Los 
campesinos no poseen títulos de propiedad, lo que dificulta el acceso a créditos, subsidios y programas de apoyo al agro.

La disputa entre la territorialidad campesina y la territorialidad del capital trae consecuencias en la gestión del territorio: para el caso particular se han visto afectados en mayor medida los intereses campesinos en relación a su apuesta agrícola de producción diversificada de alimentos y de ordenamiento de su territorio según las necesidades de la población que habita la zona, contrariamente al capital que plantea una producción basada en el monocultivo y en el latifundio, que afecta no solo el medio ambiente, sino la identidad y la vocación campesina.

\section{Consideraciones finales}

Las ZRC surgen en un contexto de demandas sociales por el acceso a la tierra y el manejo del territorio. De esta manera, se constituyen como un escenario de reivindicación de derechos del campesinado. No obstante, la implementación de estas Zonas ha estado marcada por apuestas de desarrollo con intereses disímiles donde las relaciones desiguales de poder acentúan las brechas de exclusión de los pobladores, quienes ven afectados sus procesos de planificación y gestión territorial por las proyecciones que el modelo extractivista tiene en estas áreas caracterizadas por sus posición geoestratégica y la riqueza de recursos naturales.

El territorio adquiere diferentes significaciones para el capital y el campesinado. Para el campesinado el territorio constituye el espacio en el que se desarrolla y fortalece su identidad, es su finalidad, mientras que para el capital el territorio es visto solo como un objeto o mercancía, como una posibilidad de incrementar el lucro. En esta disputa territorial media el Estado que, generalmente, legisla a favor de los intereses del capital materializado en el desarrollo de la agroindustria de la palma africana, la minería de oro y la explotación de hidrocarburos. Además, desconoce la figura del campesino que entra a ser defendida por los movimientos socioterritoriales que presionan al Estado para que garantice los derechos del campesinado sobre el territorio. 
La ZRC-VRC refleja los conflictos actuales en Colombia del uso del suelo como resultado de la coexistencia de territorialidades con enfoques diferentes de desarrollo que ocasionan discordias entre el Estado, el Capital y el Campesinado. Estas tensiones pueden afectar las proyecciones respecto a la construcción de paz en los territorios al hacer imposible la implementación de los Acuerdos en lo referente a la formalización de la propiedad rural en el marco de la legislación actual, y las consecuencias que de esto se derivan para el fortalecimiento de la economía campesina en tanto que sin formalización de la propiedad se dificulta el acceso a los diferentes programas y proyectos destinados al Desarrollo Rural Integral planteado en los Acuerdos de paz.

\section{Referencias bibliográficas}

ACVC. (2013). Plan de Desarrollo Sostenible. Barrancabermeja: ACVC.

ACVC. (2015). Caracterización biológica del sur de la serranía de san Lucas.

Recuperado de http://prensarural.org/spip/spip.php?article16506

Agencia Prensa Rural. (22 de Febrero de 2011). Agencia Prensa Rural: El Incoder levantó la suspensión irregular de la Zona de Reserva Campesina del valle del río Cimitarra. Recuperado de http://prensarural.org/spip/spip.php?article5363 Agnew, J., y Oslender, U. (2010). Territorialidades superpuestas, soberanía en disputa: lecciones empíricas desde América Latina. Tabula Rasa, 13, 191-213. Recuperado de http://www.revistatabularasa.org/numero13/territorialidadessuperpuestas-soberania-en-disputa-lecciones-empiricas-desde-america-latina/ Blanco, S. (2012). Reconfiguración territorial y cultivo de palma africana en el Magdalena Medio. El caso de San pablo sur de Bolívar. (Tesis de Maestría) Pontificia Universidad Javeriana, Facultad de Ciencia Política, Estudios Latinoamericanos. Recuperado de http://hdl.handle.net/10554/2345

Capel, H. (2016). Las ciencias sociales y el estudio del territorio. Revista Bibliográfica de Geografía y Ciencias Sociales, 21(1149), 1-38. Recuperado de http://www.ub.edu/geocrit/b3w-1149.pdf

Catastro Minero Colombiano. (2013). Consulta de títulos: Remedios. Recuperado de http://www.cmc.gov.co:8080/CmcFrontEnd/consulta/index.cmc

Cruz, C. y González, D. (2014). De la participación, organización y acción del campesinado en Colombia: la experiencias de ANZORC. CLIVATGE, 4, 61-80. Recuperado de http://revistes.ub.edu/index.php/clivatge/article/ view/15883/18976 
Equipo Nizkor y Derechos Human Rights. (eds.) (2001). Colombia Nunca Más . Crímenes de Lesa Humanidad. Zona XIV. Tomo I-NUNCA MÁS. Recuperado de http://www.derechos.org/nizkor/colombia/libros/nm/z14I/index.html

FARC-EP; Gobierno Nacional. (2016). Acuerdo final para la terminación del conflicto y la construcción de una paz estable y duradera. Recuperado de https:// www.mesadeconversaciones.com.co/sites/default/files/24-1480106030.111480106030.2016nuevoacuerdofinal-1480106030.pdf

FEDEPALMA. (2012). Extractora Loma Fresca S.A.: un proyecto que se perfila como referente ambiental. El palmicultor, 480, 12-13. Recuperado de http:// publicaciones.fedepalma.org/index.php/palmicultor/article/view/10114/10105

Fernandes, B. M. (2004). Questão Agrária: conflitualidade e desenvolvimento territorial. Biblioteca Digital do Desenvolvimiento. Recuperado de http://bibspi. planejamento.gov.br/bitstream/handle/iditem/564/Quest\%C3\%A3o\%20 agr $\% \mathrm{C} 3 \% \mathrm{~A} 1$ ria_conflitualidade $\% 20 \mathrm{e} \% 20$ desenvolvimento $\% 20$ territorial. pdf?sequence $=1$

Fernandes, B. M. (2005). Movimentos socioterritoriais e movimentos socioespaciais: contribuição teórica para uma leitura geográfica dos movimentos sociais. Biblioteca CLACSO: OSAL. Recuperado de http:// biblioteca.clacso.edu.ar/clacso/osal/20110312111042/34MFernandes.pdf

Fernandes, B. M. (2008). Entrando no território dos territórios. Recuperado de http://www2.fct.unesp.br/nera/artigodomes/3artigodomes_2008.pdf

Flores, M. (2007). La identidad cultural del territorio como base de una estrategia de desarrollo sostenible. Revista Opera, 7, 35-54. Recuperado de http:// revistas.uexternado.edu.co/index.php/opera/article/view/1183/1122

Guerra, G. (9 de Febrero de 2015). Comunicación personal. (C. M. Quijano-Mejía, Entrevistador)

IDEAM. (2006). Zonas de reservas forestales de Colombia. Ley 2 de 1959: Atlas temático. Recuperado de http://documentacion.ideam.gov.co/openbiblio/ bvirtual/019679/019679.htm

INCORA. (25 de Noviembre de 1996). Acuerdo 024. Recuperado de http:// biblovirtual.minambiente.gov.co:3000/DOCS/NORMAS/1996/Acuerdos/ AC00241996.doc

Llanos, L. (2010). El concepto del territorio y la investigación en las Ciencias Sociales. Agricultura, sociedad y desarrollo, 7(10), 207-220. Recuperado de http://www.colpos.mx/asyd/volumen7/numero3/asd-10-001.pdf

Méndez, Y. (2013). Derecho a la tierra y al territorio, justicia y Zonas de Reserva Campesona: el caso del valle del río Cimitarra. (Tesis de Maestría). Pontifica Universidad Javeriana, Facultad de estudios ambientales y rurales, Desarrollo Rural. Recuperado de http://hdl.handle.net/10554/12429 
Murillo, A. (1994). Un mundo que se mueve como un río, historia regional del Magdalena Medio. Bogotá: Instituto colombiano de antropología.

Nates, B. (2011). Soportes teóricos y etnográficos sobre conceptos de territorio. Revista Co-herencia, 8(14), 209-229. Recuperado de http://publicaciones. eafit.edu.co/index.php/co-herencia/article/view/283/286

Pastrana, F. (2014). Culturas campesinas, etnicas en conflictos territoriales en Colombia. Kavilando, 6(1), 63-71. Recuperado de http://revistakavilando. weebly.com/uploads/1/3/6/3/13632409/revkav_vol6n1_8culturas_ campesinas_etnicas_conflicto_fpl.pdf

Pérez, M. (2004). La conformación territorial en Colombia: entre el conflicto, el desarrollo y el destierro. Cuadernos de desarrollo rural, 51, 61-90. Recuperado de http://www.javeriana.edu.co/ier/recursos_user/documentos/ revista51/61_90.pdf

PNUD y ACVC. (2014). Estudio participativo de tenencia de la tierra yel territorio, usos y conflictos en la ZRC del valle del río cimitarra. Barrancabermeja: PNUD - ACVC.

Porto-Goncalves, C. W. (2003). A geograficidade do social: uma contribuição para o debate metodológico sobre estudos de conflito e movimentos sociais na América Latina. En J. Seoane, Movimientos sociales y conflictos en América Latina (p. 288). Buenos Aires, Argentina: CLACSO.

Programa de Desarrollo y Paz del Magdalena Medio. (2012). Caracterización étnico cultural y socioeconómica del Consejo Comunitario afrodescendiente de Caño Bodegas. Yondó: PDPMM.

República de Colombia. Ley 160 de 1994. Por la cual se crea el Sistema Nacional de Reforma Agraria y Desarrollo Rural Campesino, se establece un subsidio para la adquisición de tierras, se reforma el Instituto Colombiano de la Reforma Agraria y se dictan otras disposiciones. Bogotá: Congreso de la República.

Revita Semana. (22 de Junio de 2013). Reportaje: Por qué arde el Catatumbo. Recuperado de http://www.semana.com/nacion/articulo/ reportaje-que-arde-catatumbo/348448-3

Rodríguez, C., Lorenzo, O. y Herrera, L. (2005). Teoría y práctica del análisis de datos cualitativos. Proceso general y criterios de calidad. Revista Internacional de Ciencias Sociales y Humanidades, SOCIOTAM, 15(2), 133-154. Recuperado de http://www.redalyc.org/pdf/654/65415209.pdf

Rodríguez, G., Gil, J. y García, E. (1996). Metodología de la investigación cualitativa. España: Ediciones Algibe.

Ruíz, M. (2015). Territorio y ambiente en las Zonas de Reserva Campesina de Colombia. EUTOPÍA, 45-56. DOI: https://doi.org/10.17141/ eutopia.8.2015.1826 
Silva, D. (2016). Construcción de territorialidad desde las organizaciones campesinas en Colombia. Polis, Revista Latinoamericana, 43, 633-654. Recuperado de https://polis.revues.org/11786

Stake, R. (1999). Investigación con estudio de casos. Madrid: Ediciones Morata.

Yin, R. (1989). Case Study Research: Design and Methods, Applied social research. Newbury Park CA: Sage.

Zibechi, R. (2007). Los movimientos sociales latinoamericanos: tendencias y desafios. Los movimientos sociales latinoamericanos: tendencias y desafíos. OSAL: Observatorio Social de América Latina, 9. Recuperado de http:// biblioteca.clacso.edu.ar/clacso/osal/20110216015830/18zibechi.pdf

Cómo citar este artículo:

Quijano-Mejía, C. y Linares-García, J. (2017). Zonas de Reserva Campesina: territorialidades en disputa. El caso del Valle del río Cimitarra. Prospectiva, 24, 225-251. Doi: 10.25100/prts.v\%vi\%i.4478 